\title{
CMC-VAP Regimen
}

National Cancer Institute

\section{Source}

National Cancer Institute. CMC-VAP Regimen. NCI Thesaurus. Code C161951.

A chemotherapy regimen consisting of high-dose cyclophosphamide, methotrexate, and lomustine (CMC) alternating with vincristine, doxorubicin, and procarbazine (VAP) that may be used in the treatment of small cell lung cancer (SCLC). 